\title{
Clinical aspects of Angle class II/1 malocclusion during the eruption of the 12-year-old molar
}

Aspecte clinice ale malocluziei II/1 Angle în timpul erupţiei molarului de 12 ani

\author{
Ionela Teodora Dascălu1, Adina Magdalena Bunget ${ }^{1}$,Evantia Coleş ${ }^{3}$, P. Mărăşescư \\ Felicia Mărăşescu', Marina Amărăscu ${ }^{4}$, Andreea Gabriela Nicola², Mihaela Stan ${ }^{5}$, \\ Iren Moraru' ${ }^{6}$, C. Dăguci ${ }^{7}$, Cristian Funieru ${ }^{8}$, Edwin Sever Bechir ${ }^{9}$ \\ ${ }^{1}$ Disciplina de Ortodonţie, Universitatea de Medicină şi Farmacie, Craiova, România \\ ${ }^{2}$ Disciplina de Prevenţie Orodentară, Universitatea de Medicină şi Farmacie, Craiova, România \\ ${ }^{3}$ Disciplina de Tehnologie a Protezelor Dentare, Universitatea de Medicină şi Farmacie, \\ Craiova, România \\ ${ }^{4}$ Disciplina de Morfologie şi Semiologie a Sistemului Stomatognat, \\ Universitatea de Medicină şi Farmacie, Craiova, România \\ ${ }^{5}$ Disciplina de Materiale Dentare, Universitatea de Medicină şi Farmacie, Craiova, România \\ ${ }^{6}$ Disciplina de Endodonţie, Universitatea de Medicină şi Farmacie, Craiova, România \\ ${ }^{7}$ Disciplina de Sănătate Orală, Universitatea de Medicină şi Farmacie, Craiova, România \\ ${ }^{8}$ Disciplina de Prevenţie Orodentară, Universitatea de Medicină şi Farmacie „Carol Davila", \\ Bucureşti, România \\ ${ }^{9}$ Disciplina de Parodontologie, Universitatea de Medicină şi Farmacie, Tg. Mureş, România
}

\begin{abstract}
Introduction. The vicious habit of sucking the thumb is an etiological factor of Angle Class II/ 1 malocclusion. Case presentation. In the clinical case that we intend to present, the main goal of the treatment was to recover the occlusion and the functions of the dento-maxillary complex. The treatment relied on the use of a fixed appliance. The sagittal inocclusion was thus reduced and the parameters of occlusion were brought to normality.

Conclusions. We consider that the period of orthodontic treatment was reduced be-cause the climax of the bones growth took place at the same time with the eruption of the 12-year-old molars.
\end{abstract}

Keywords: II/1 Angle malocclusion, the sucking of the thumb, the eruption of the 12-year-old molar

\section{REZUMAT}

Introducere. Obiceiul vicios de sugere a policelui reprezintă un factor etiologic al malocluziei II/1 Angle. Prezentare de caz. În cazul clinic pe care-l prezentăm scopul tratamentului a fost de restabilire a ocluziei şi a funcţiilor aparatului dento-maxilar. Tratamentul s-a realizat cu aparat fix. S-a obţinut reducerea inocluziei sagitale cu tendinţa la normalizare a parametrilor ocluziei.

Concluzii. Considerăm că timpul tratamentului ortodontic s-a scurtat deoarece a fost surprins puseul de creştere osoasă odată cu erupţia molarilor de 12 ani.

Cuvinte cheie: malocluzie II/1 Angle, sugerea policelui, molar de 12 ani în erupţie

\section{INTRODUCERE}

Sugerea policelui după vârsta de 5 ani este considerată un obicei vicios care poate determina mo- dificări morfologice la nivelul aparatului dentomaxilar (1). Astfel, sugerea policelui devine unul dintre principalii factori etiologici implicați în apariția malocluziei clasa II/1 Angle. 
Instalarea ca obicei vicios ar putea avea o „origine emoțională“ (Szpiczac, 1975, citat de Grivu O. şi col.) (2). Încă din 1969, Peterson (citat de Voinea şi col. 1996) considera că ,sugerea policelui apare în urma lipsei de contact fizic şi afectiv din partea mamei“"(3).

În literatura de specialitate autorii sunt de acord că, prin sugerea degetului, în cavitatea bucală perfect închisă apare un vid care permite părților moi să determine modificări scheletale la nivelul aparatului dento-maxilar.

\section{CAZ CLINIC}

Pacient în vârstă de 12 ani s-a prezentat în cabinetul ortodontic în scopul îmbunătățirii aspectului fizionomic.

Pacientul afirmă că a prezentat obiceiul vicios de sugere a policelui până la vârsta de 7 ani.

Examenul exooral în normă frontală a evidențiat o față îngustă, dreptunghiulară, cu etajul inferior uşor mărit, aripile nasului aplatizate şi hipotone, asimetrie facială cu jumătatea facială stângă mai mică decâ cea dreaptă şi uşoară deviere spre dreapta a mentonului. Buza superioară prezintă un filtru bine exprimat fără vizibilitatea grupului incisiv maxilar. Şanțul labio-mentonier este uşor accentuat.

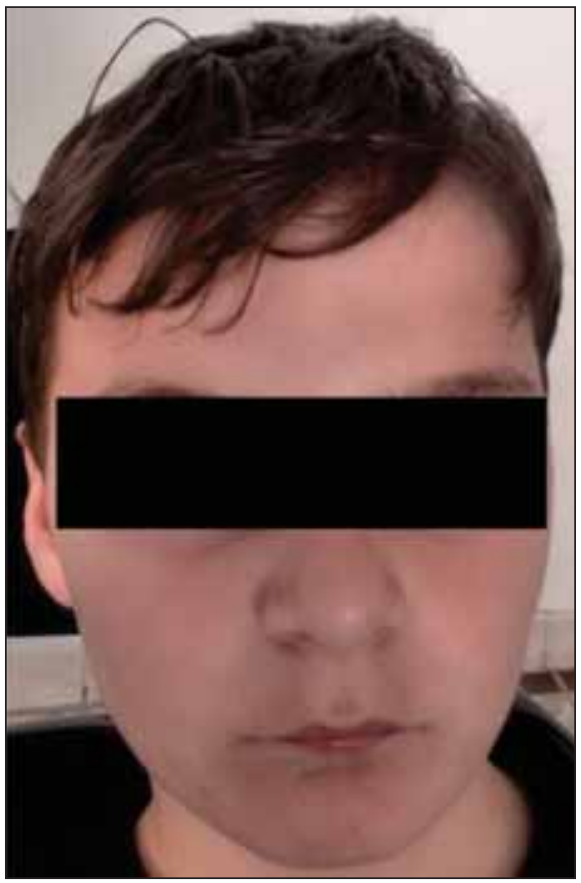

FIGURA 1. Fotografie exoorală în normă frontală

La examenul exooral în normă laterală am constatat un profil convex cu menton retras, procheilie superioară şi retrocheilie inferioară, buza inferioară fiind poziționată în spatele grupului frontal maxilar.

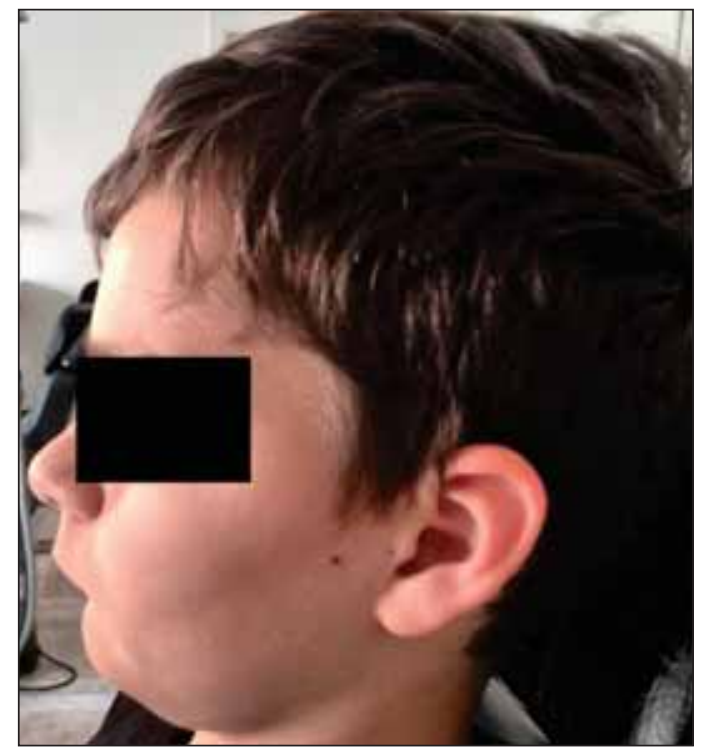

FIGURA 2. Fotografie exoorală profil stânga

Endooral în normă frontală, în ocluzie se poate observa supraacoperirea de 1/1 în zona frontală cu alinierea fără spațiere a frontalilor superiori.
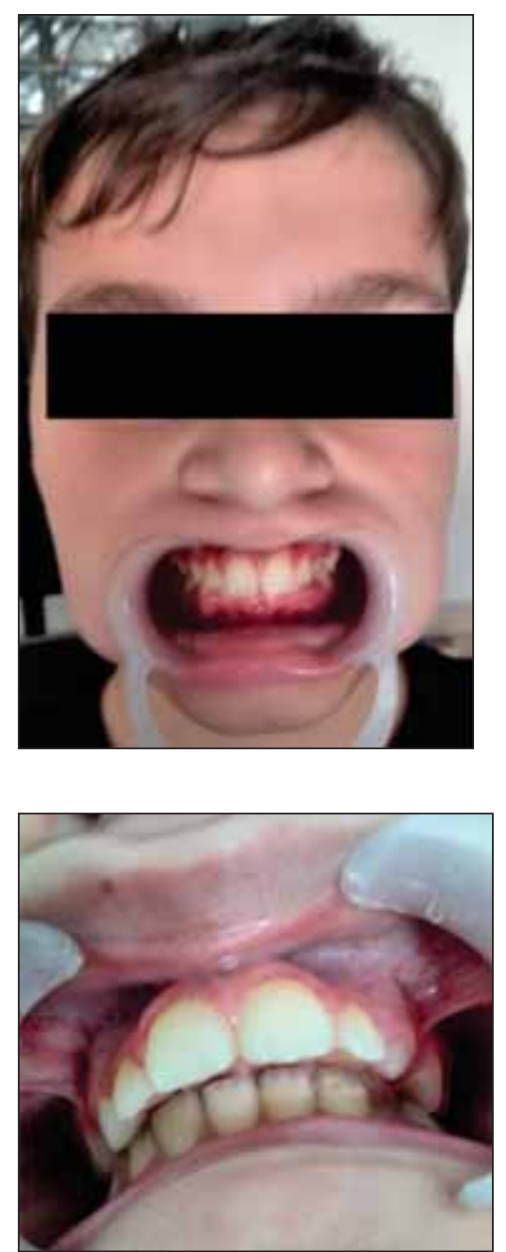

FIGURA 3. Fotografie endoorală în ocluzie 


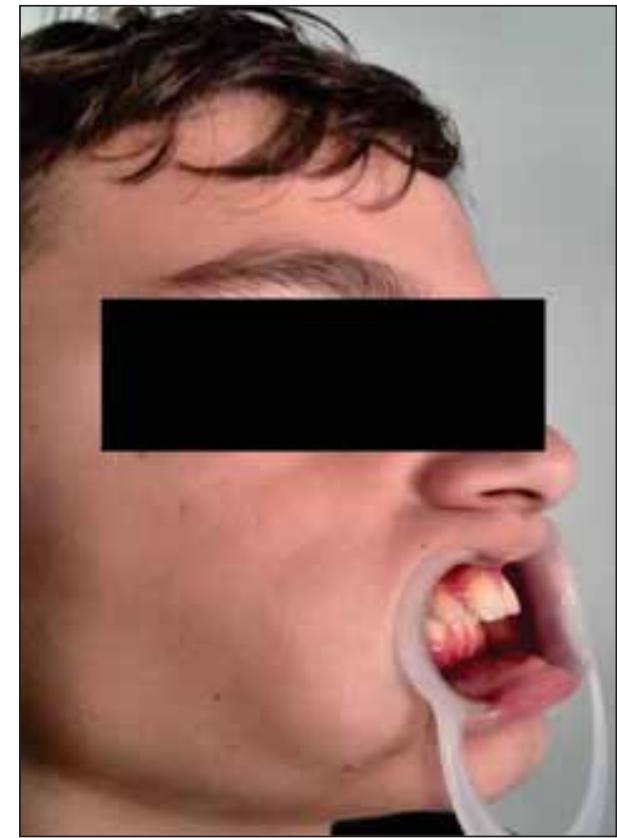

FIGURA 4. Fotografie endoorală în ocluzie profil dreapta

Un alt aspect al arcadelor pune în evidență contactul marginilor incizale inferioare cu mucoasa bolții palatine şi devierea la stânga a liniei interincisive inferioare.

Endooral în ocluzie în normă laterală remarcăm supraacoprire de $1 / 1$ cu inocluzie sagitală şi vestibuloversia cu aliniere a incisivilor superiori.

Analiza modelelor de studiu evidențiază o malocluzie cu rapoarte distalizate bilateral la nivelul molarilor şi caninilor cu devierea la stânga a liniei interincisive şi supraacoperire de 1/1 în zona frontală.

Pe ortopantomogramă observăm prezența mugurilor molarilor 3, dentiție permanentă şi imaginea în evantai a regiunii incisive. Pe teleradiografia de profil s-au înregistrat modificări ale valorilor unghiurilor ANB, IMPA şi interincisiv ceea ce confirmă modificările scheletale existente.

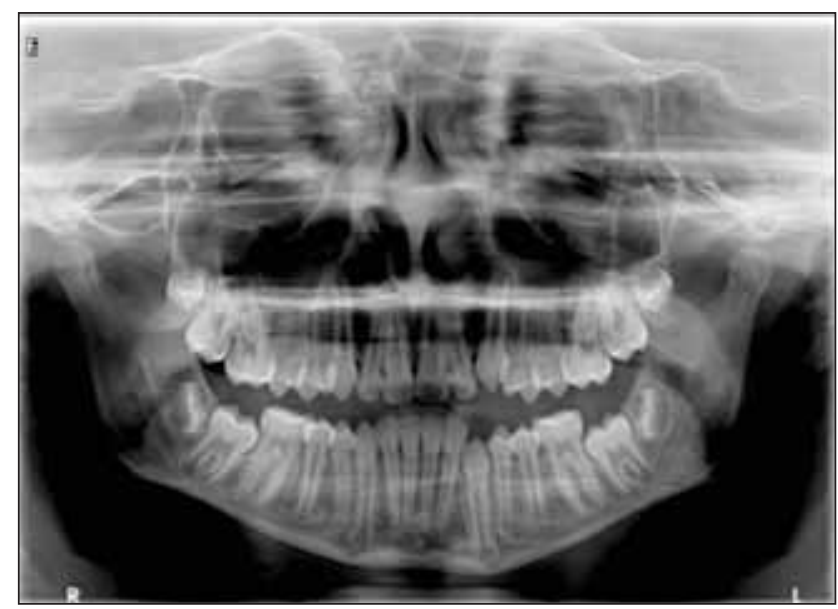

FIGURA 6. Ortopantomogramă

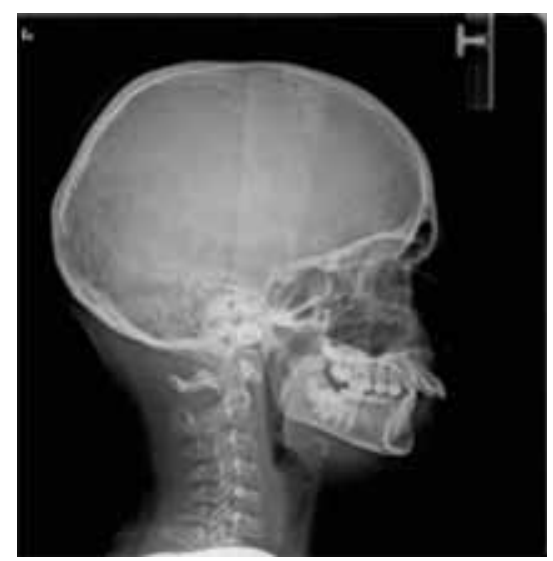

FIGURA 7. Teleradiografie de profil

\section{Nivel de malocluzie: Clasa II}

TABELUL 1. Interpretare teleradiografie de profil

\begin{tabular}{|l|l|c|c|}
\hline Label & Relation & Unit & Value \\
\hline FMA & $\begin{array}{l}\text { Frankfort Horizontal__ } \\
\text { Plane, Mandibular_Plane }\end{array}$ & degree & 22.0 \\
\hline FMIA & $\begin{array}{l}\text { Frankfort Horizontal_ } \\
\text { Plane, Lower Incisor } \\
\text { Axis }\end{array}$ & degree & 49.0 \\
\hline IMPA & $\begin{array}{l}\text { Lower_Incisor_Axis, } \\
\text { Mandibular_Plane }\end{array}$ & degree & 108.0 \\
\hline
\end{tabular}
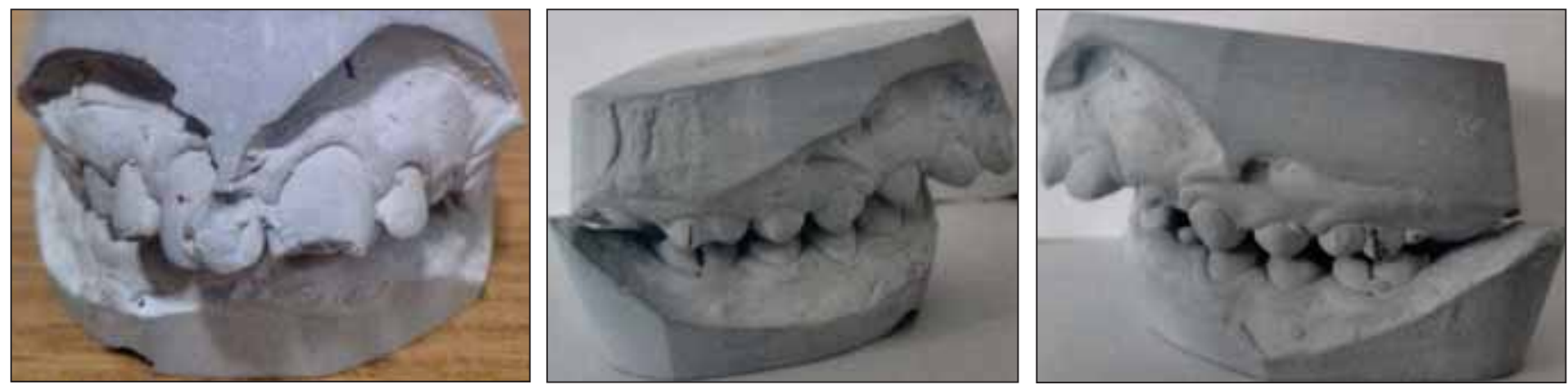

FIGURA 5. Fotografie modele de studiu inițiale 


\begin{tabular}{|l|l|c|c|}
\hline Label & Relation & Unit & Value \\
\hline S-N-A & S-N-A & degree & 83.4 \\
\hline S-N-B & S-N-B & degree & 77.4 \\
\hline A-N-B & A-N-B & degree & 6.1 \\
\hline AO & A, Occlusal_Plane & $\mathrm{mm}$ & 14.7 \\
\hline BO & B, Occlusal_Plane & $\mathrm{mm}$ & 15.3 \\
\hline OP-FH & $\begin{array}{l}\text { Occlusal_Plane, } \\
\text { FrankfortHorizontal_Plane }\end{array}$ & degree & 5.0 \\
\hline $\begin{array}{l}\text { Chin Thickness } \\
\text { (TC) }\end{array}$ & Pog', N-B & $\mathrm{mm}$ & 14.8 \\
\hline $\begin{array}{l}\text { Upper Lip } \\
\text { Thickness (UL) }\end{array}$ & Ls, N-B & $\mathrm{mm}$ & 24.4 \\
\hline $\begin{array}{l}\text { Anterior Facial } \\
\text { Height (AFH) }\end{array}$ & Me, Palatal_Plane & $\mathrm{mm}$ & 47.6 \\
\hline $\begin{array}{l}\text { Posterior Facial } \\
\text { Height (PFH) }\end{array}$ & Co, Mandibular_Plane & $\mathrm{mm}$ & 32.7 \\
\hline $\begin{array}{l}\text { Z-angle 1 } \\
\text { FrankfortHorizontal_ } \\
\text { Plane, Ls-Pog' }\end{array}$ & degree & 61.0 \\
\hline
\end{tabular}

\section{REZULTATE ŞI DISCUŢII}

Pe modelele inițiale se observă absența molarilor de 12 ani. Tratamentul ortodontic a surprins puseul de creştere osoasă odată cu erupția molarilor de 12 ani.
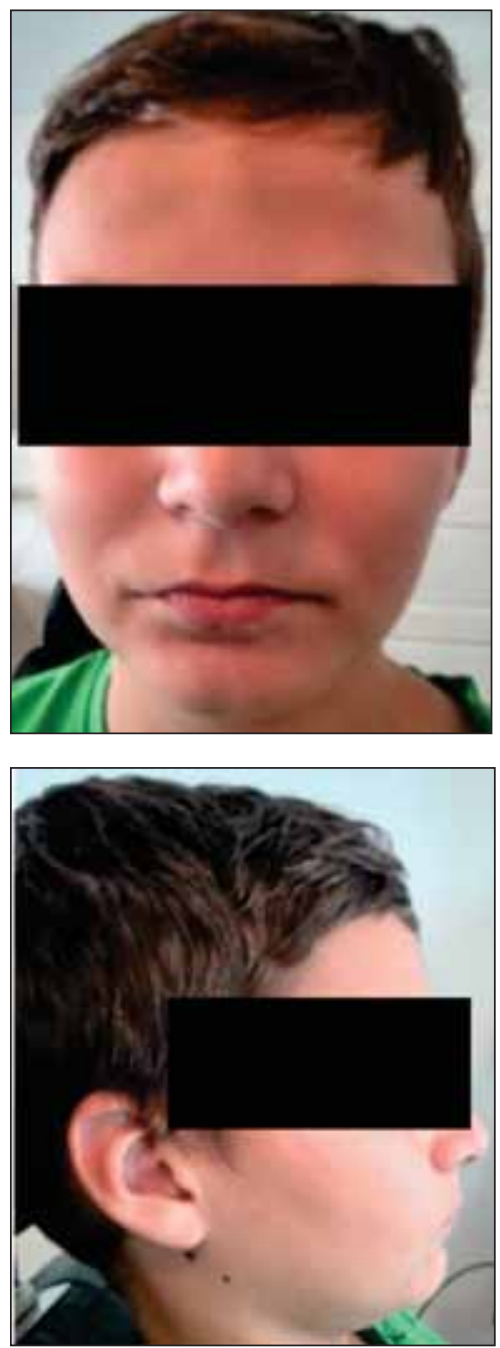

FIGURA 8.

Fotografii exoorale față şi profil dreapta în timpul tratamentului
În acest caz am optat pentru un tratament cu aparat ortodontic fix. Tratamentul s-a axat pe lărgirea arcadelor alveolo-dentare, restabilirea rapoartelor ocluzale neutrale şi reducerea spaţiului de inocluzie sagitală.

Pe parcursul tratamentului am observat tendința de restabilire a funcțiilor aparatului dento-maxilar şi îmbunătățirea aspectului estetic facial atât în normă frontală cât şi laterală.

Endooral se poate observa tendinţa de restabilire a parametrilor unei ocluzii normale.

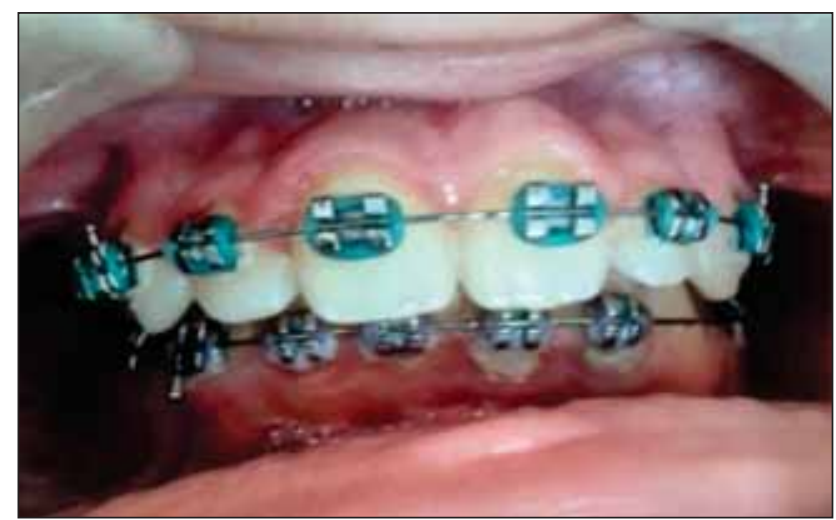

FIGURA 9. Fotografie endoorală în normă frontală în ocluzie în timpul tratamentului

În unele scheme de tratament ale malocluziei clasa II/1 Angle cu un overjet accentuat se realizează într-o primă etapă distalizarea grupului lateral şi apoi retruzia incisivilor superiori pentru a reduce inocluzia sagitală (4).

În cazul nostru, tratamentul a urmărit restabilirea rapoartelor neutrale şi a spaţiului de inocluzie sagitală în acelaşi timp.

Actualmente este analizat timpul pe care se întinde tratamentul ortodontic. Sunt specialişti care au făcut studii comparative ale timpului de tratament ortodontic în funcție de începerea tratamentului înainte sau după pubertate. S-a observat că timpul de tratament ortodontic este mai lung atunci când se începe după perioada de pubertate (5).

\section{CONCLUZII}

Molarii de 12 ani în erupție ar putea fi un motiv pentru tendința de restabilire a unei ocluzii normale într-un timp relativ scurt.

\section{Notă}

Toți autorii au participat în mod egal la realizarea acestui articol. 


\section{BIBLIOGRAFIE}

1. Constantina Roman, Compendiu de ortodonţie - Curs universitar destinat studenţilor stomatologi, Ed. Ovidius Univerity Press Constanţa 2003, pg. 121-122;

2. Ileana Tudor, Grivu O., Drăgan I., Daniela Jumanca, Psihologie pentru stomatologi, Ed. Mirton, Timişoara, 1999, pg. 38

3. Voinea C., Băilă A., Grivu O., Funcţia musculară şi aparatul dento-maxilar, Ed. Mirton, Timişoara, 1996, pg 38;
4. Katia Montanha, Class II, Division 1 Angle malocclusion with severe proclination of maxillary incisors, Dental Press $\mathrm{J}$. Orthod, Jan-Feb., 21(1): 101-109, 2016;

5. Chhibber A., Upadhyay M., Uribe F., Nanda R., Mechanism of Class II correction prepubertal and postpubertal patients with Twin Force Bite Corrector, Angle Orthod., Jul. 83 (4): 718-27, 2013. 